\title{
Alcohol and Sleep Problems in Primary Care Patients: A Report from the AAFP National Research Network
}

\author{
Daniel C. Vinson, MD, MSPH \\ Brian K. Manning, MPH \\ James M. Galliher, $P b D^{2,3,4}$ \\ L. Miriam Dickinson, $\mathrm{PhD}^{2,4}$ \\ Wilson D. Pace, MD ${ }^{2,4}$
}

Barbara J. Turner, MD, MSED, $M A^{5}$

'Department of Family and Community Medicine, University of Missouri, Columbia, Missouri

\section{${ }^{2}$ AAFP National Research Network, Leawood, Kansas}

${ }^{3}$ Department of Sociology, University of Missouri, Kansas City, Missouri

${ }^{4}$ Department of Family Medicine, University of Colorado at Denver Health Sciences Center, Denver, Colorado

${ }^{5}$ Primary Care Physician Scientist Fellowship, University of Pennsylvania, Philadelphia, Pennsylvania

\begin{abstract}
PURPOSE Hazardous and harmful drinking and sleep problems are common, but their associations among patients seen in primary care have not been examined. We hypothesized that greater levels of alcohol consumption would be associated with several self-reported sleep problems.
\end{abstract}

METHODS In a cross-sectional survey in primary care practices, 94 participating clinicians recruited up to 30 consecutive adult patients, and both clinicians and patients completed anonymous postvisit questionnaires. Patients were asked questions on demographics, alcohol consumption, cardinal symptoms of alcohol use disorders, sleep quality, insomnia, sleep apnea, and symptoms of restless leg syndrome. Multivariate analyses explored the associations of drinking status (none, moderate, or hazardous) and sleep problems, adjusting for demographics and clustering of patients within physician.

RESULTS Of 1,984 patients who responded, 1,699 (85.6\%) provided complete data for analysis. Respondents' mean age was 50.4 years (SD 17.4 years), $67 \%$ were women, and $72.9 \%$ were white. Of these, $22.3 \%$ reported hazardous drinking, $47.8 \%$ reported fair or poor overall sleep quality, and $7.3 \%$ reported a diagnosis or treatment of sleep apnea. Multivariate analyses showed no associations between drinking status and any measure of insomnia, overall sleep quality, or restless legs syndrome symptoms. Moderate drinking was associated with lower adjusted odds of sleep apnea compared with nondrinkers $(\mathrm{OR}=0.61 ; 95 \% \mathrm{Cl}$, 0.38-1.00). Using alcohol for sleep was strongly associated with hazardous drinking $(\mathrm{OR}=4.58 ; 95 \% \mathrm{Cl}, 2.97-7.08$, compared with moderate drinking).

CONCLUSIONS Moderate and hazardous drinking were associated with few sleep problems. Using alcohol for sleep, however, was strongly associated with hazardous drinking relative to moderate drinking and may serve as a prompt for physicians to ask about excessive alcohol use.

Ann Fam Med 2010;8:484-492. doi:10.1370/afm.1175.

\section{BACKGROUND}

$\mathrm{H}$ eavy episodic drinking and alcohol use disorders remain important causes of preventable morbidity and mortality in the United States. ${ }^{1-3}$ Annually, alcohol causes more than 85,000 deaths, ${ }^{4} 1.6$ million hospitalizations, ${ }^{5}$ and 4 million emergency department visits. ${ }^{6}$

Societal costs in 1998 for alcohol misuse were estimated at $\$ 184.6$ billion, including $\$ 26.3$ billion in health care costs. ${ }^{7}$ In the 2008 Behavioral Risk Factor Surveillance Survey, 53.9\% of US adults reported drinking alcohol in the past 30 days, and $15.5 \%$ had had more than 4 (for women) or 5 (for men) drinks in 1 day. ${ }^{8}$ In the 2001-2002 National Epidemiologic Survey on Alcohol and Related Conditions, $4.7 \%$ of respondents had current (pastyear) alcohol abuse and another $3.8 \%$ had alcohol dependence. ${ }^{9}$

Alcohol problems are as prevalent as hypertension or type 2 diabetes 
in primary care patients, but they are less likely to be detected or diagnosed. ${ }^{10,11}$ Patients support physician screening about alcohol use, ${ }^{12}$ and primary care practices offer excellent opportunities to deliver effective brief interventions to prevent and address alcohol use problems. ${ }^{11}$ Recommendations for routine screening, ${ }^{13}$ however, have been difficult to integrate into routine care because of the many other demands on these practices ${ }_{1}^{14}$ including clinicians' discomfort in addressing alcohol consumption when it is not on the patient's agenda. ${ }^{15}$ This study is one of a set of studies predicated on the premise that clinicians may place a greater priority on alcohol screening if associations are found with other conditions that are commonly seen in primary care patients. ${ }^{16}$

Sleep problems are also prevalent among US adults. Nationally, 27\% of adults reported occasional insomnia, and $9 \%$ reported severe, nightly insomnia. ${ }^{17}$ Similarly, $10 \%$ of a primary care sample reported nightly insomnia ${ }^{18}$; and in another primary care sample, 55\% of patients reported excessive daytime sleepiness, 34\% reported insomnia, $28 \%$ had symptoms of restless legs syndrome, and $13 \%$ reported having had witnessed apnea. ${ }^{19}$ Sleep problems have been associated with a broad range of medical conditions, including mental disorders, cardiovascular, and respiratory diseases. ${ }^{18}$

Alcohol and sleep problems are likely to be interrelated in several ways. ${ }^{20}$ In a population-based study, persons with chronic insomnia reported use of alcohol at bedtime for sleep about twice as often (12.9\%) as an age-sex matched control group (5.6\%), ${ }^{21}$ even though moderate doses of alcohol may not be effective in inducing sleep, ${ }^{22}$ and higher doses can cause rebound insomnia later in the night. ${ }^{23}$ In another populationbased sample, insomnia was prospectively associated with a twofold higher risk of developing alcohol abuse. ${ }^{24}$ Few studies, however, have investigated the association of sleep problems with alcohol use in a large sample of primary care patients. We hypothesized that greater levels of alcohol consumption would be associated with a variety of self-reported sleep problems.

\section{METHODS}

This cross-sectional study was conducted in the American Academy of Family Physicians National Research Network (AAFP NRN) and several affiliated networks (Kentucky Ambulatory Network, Research Involving Outpatient Settings Network, Missouri's Show-Me Research Network, and State Networks of Colorado Ambulatory Practices and Partners). Primary care clinicians were recruited through e-mails, personalized letters, and an article appearing in AAFP News Now (Sept $2007^{25}$ ). Clinicians who agreed to participate were asked to enroll up to 30 patients from consecutive visits during 3 half-days (or its equivalent) over 2 weeks.

Patients were provided an informational sheet about the study at the start of their office visit and were not required to sign an informed consent form. Eligible patients were 18 years old, cognitively intact, not in severe distress, and able to read English. Determining eligibility was the responsibility of the study clinician or practice study coordinator. Participation did not affect the care that was received by study patients.

For patients who agreed to participate, both patient and clinician were asked to complete questionnaires immediately after the visit. Patients were instructed to seal their anonymous 23-item self-administered questionnaire in an accompanying envelope and leave it at the front desk upon checking out. The 2 questionnaires were linked by a unique study identification number. Data were collected from October 2007 to September 2008.

We conducted a pilot study in August 1997. Thirtyeight primary care patients were asked to complete the patient questionnaire and provide feedback to investigators on layout, readability, clarity, and question understanding. The study was approved by the AAFP Institutional Review Board (IRB) and 11 local IRBs. For practices without a local IRB, their clinicians participated as unaffiliated investigators under the AAFP's Federalwide Assurance.

\section{Patient Measures}

\section{Sleep Problems}

For the patient questionnaire we asked questions about problems with sleep using lay language, including typical sleep duration, initial and late insomnia, taking medication for sleep, daytime somnolence, overall sleep quality, using alcohol for sleep, sleep apnea, and symptoms of restless legs (available at: http://www.aafp .org/online/en/home/clinical/research/natnet/studies /alpha-studies/prism-study.html). In composing these questionnaire items, we considered questions from the Pittsburgh Sleep Quality Index ${ }^{26}$ and the Global sleep Assessment Questionnaire, ${ }^{27}$ but selected and adapted them for brevity, ease of reading, and self-administration. Sleep apnea was defined by the patient's report of a diagnosis by a health care professional or treatment for this condition.

\section{Drinking Status}

The patient questionnaire included 5 alcohol questions. Three were the quantity-frequency questions from the Alcohol Use Disorders Identification Test (AUDIT-C) ${ }^{28,29}$ : "In the past 12 months, how often have you had a drink containing alcohol?" "... how many drinks containing alcohol have you had on a 
typical day when you are drinking?" and "... how often have you had 6 or more drinks on 1 occasion?" They were scored from 0 to 4 points and summed, with possible scores ranging from 0 to 12 where 0 reflects no alcohol use. A positive finding for hazardous drinking is a score of 4 or more for men and 3 or more for women. The other 2 alcohol questions were derived from questions in the Diagnostic Interview Schedule that are sensitive and specific in identifying alcohol use disorders $\mathrm{s}^{30,31}$ based on diagnostic criteria in the 4 th edition of the Diagnostic and Statistical Manual of Mental Disorders (DSM-IV) ${ }^{32}$ : "In the past 12 months, how often have you had a lot more to drink than you intended to have?" and "In the past 12 months, how often have you been under the influence of alcohol in situations where you could have caused an accident or gotten hurt?" For these 2 questions, a report of "monthly" or more often on either item or "less than monthly" on both was considered a positive screen for hazardous drinking. In an independent validation study, these 2 questions had a sensitivity of $88 \%$ and specificity of $90 \%$ in detecting DSM-IV-defined alcohol use disorders. ${ }^{31}$ Patients' drinking status was classified into 3 categories based on their responses to all 5 alcohol questions. A nondrinker responded negatively to all questions. A moderate drinker acknowledged alcohol use but was negative on both the AUDIT-C and the DSM-IV-based questions. A hazardous drinker screened positive on either AUDIT-C or DSM-IV-based questions.

\section{Statistical Analysis}

We aimed to recruit 100 clinicians with 25 patients each for a total sample size of approximately 2,500. A sample this large would allow us to estimate prevalence rates for both alcohol problems and selected sleep problems and provide enough power to detect relatively small differences between categories of drinkers on sleep problems of interest.

We first examined statistical associations (using either $\chi^{2}$ tests or analysis of variance for bivariate analysis and ordered logistic regression for multivariate analysis) of the 3-level drinking status variable with patient demographics to determine comparability with published studies. This step was followed with bivariate analysis between drinking status and the 9 sleep items ( $\chi^{2}$ for sleep apnea and Kruskal-Wallis for other items). We used multivariate linear or logistic regression for models with the sleep problems as the dependent variable, adjusted for demographics and clustering of patients within clinicians.

To examine associations between demographic variables and drinking status, we estimated models with drinking status as the dependent variable. Because drinking status in this report has 3 levels, we used ordered logistic regression. To evaluate whether the odds ratios generated by ordered logistic regression were proportional, we used 2 dichotomous variables for drinking status, one comparing all drinkers with nondrinkers and the second comparing hazardous drinkers with all others. Comparison of results using ordered logistic regression (which assumes proportionality of the odds) with results from the 2 separate binary logistic models (no such assumption) confirmed the assumption of proportionality; that is, coefficients from the 2 logistic regression models were similar to each other and to the coefficient from the ordered regression model. The results from ordered logistic regression are therefore reported.

Analyses throughout used a $P$ value of less than or equal to .05 for assessing statistical significance. All multivariate models controlled for age, sex, 4-level educational attainment, and clustering by clinician. With ordinal variables (eg, educational attainment), we created dummy variables with the lowest category as the referent group. Across all analyses, we used SPSS 17 (SPSS for Windows, SPSS, Inc, Chicago, Illinois), SAS 9.1 (SAS Institute, Inc., Cary, North Carolina), and Stata SE 10.1 (StataCorp, LP, College Station, Texas).

\section{RESULTS}

\section{Study Sample}

The project team recruited 94 clinicians from 40 practices into the study. There were 2,173 eligible patients invited of whom 1,984 (91\%) enrolled for an average recruitment of 21 patients per clinician $(\mathrm{SD}=7$; range, 1-30). There were an additional 221 patients invited into the study who were ineligible, though study practices were not asked to record the specific reasons for patient ineligibility. Another 124 patients were inadvertently not invited into the study whose eligibility was not determined. Although we recruited 94 of our established quota of 100 clinicians, we enrolled only $1,984(79 \%)$ of our desired sample size of 2,500.

Of the 1,984 enrolled patients, 1,825 (92\%) returned usable patient questionnaires. The other 159 patients either did not return a questionnaire or returned it with no responses even though their study clinicians returned postvisit questionnaires. Complete data on the 5 alcohol items were obtained from 1,733 (95\%) of 1,825 patients. Of these, valid data on sex, age, and education were obtained from 1,699 patients (85.6\% of those who enrolled), and these respondents comprise the sample for analyses reported here. Data for the various sleep items were provided by $96 \%$ to $100 \%$ of these 1,699 .

We compared the 1,699 respondents (with complete data) with the other 126 who returned usable 


\begin{tabular}{|lc|}
\hline \multicolumn{2}{|l}{ Table 1. Patient Demographics $(\mathbf{N}=1,699)$} \\
\hline Demographic Factor & Value \\
\hline Sex, No. (\%) & $1,137(66.9)$ \\
Female & $562(33.0)$ \\
Male & $50.4(17.4)$ \\
Age, mean (SD), y & \\
Education, No. (\%) & $177(10.4)$ \\
Less than high school & $539(31.7)$ \\
High school or GED & $442(26.0)$ \\
Some college & $541(31.8)$ \\
College graduate & \\
Race and ethnicity, No. (\%) & $1,228(72.3)$ \\
White & $218(12.8)$ \\
African-American & $139(8.2)$ \\
Hispanic ethnicity (of any race) & $239(14.1)$ \\
Other & $14(0.8)$ \\
Missing & \\
\hline GED $=$ general equivalency diploma. &
\end{tabular}

questionnaires (with some incomplete data) across 19 variables (4 demographic, 9 sleep, 5 alcohol items, and drinking status). Respondents with complete data differed significantly $(P<.05)$ from those with incomplete data on 3 items. They had higher educational attainment, were less likely to report taking medication to sleep during past 30 days, and were less likely to report drinking.

The average age of study patients was 50 years and $67 \%$ were women (Table 1). Ten percent reported less than a high school education, and 58\% reported at least some college education. Almost 3 in 4 patients identified themselves as white race.

The 5 alcohol items and their composites are shown in Table 2. Based on the AUDIT-C screen alone, 39\% of patients were classified as moderate drinkers and $21 \%$ as hazardous drinkers. On the 2-item DSM-IV measure, $8 \%$ of patients had positive screens. When these 2 screens were combined into the drinking status item used in these analyses, $40 \%$ of study patients were nondrinkers, 38\% were moderate drinkers, and 22\% were hazardous drinkers. Table 3 shows the composite of AUDIT-C and DSM-IV screening outcomes.

The AUDIT-C and DSM-IV screen were strongly associated: including all respondents, $\kappa=0.40, P<001$; and including only drinkers, $\mathrm{K}=0.34, P<.001$ (Table 2). Seventeen (3\%) of moderate drinkers and 115 (32\%) of hazardous drinkers had a positive screen on the DSM-IV composite.

\section{Drinking Status and Demographics}

Drinking status (composite of AUDIT-C and DSM-IV screens) varied significantly by sex, age, and education $(P<.001$ for each) (Table 4$)$ at the bivariate level.
Table 2. Patient Self-Reported Alcohol Consumption ( $\mathrm{N}=1,699)$

\begin{tabular}{|c|c|}
\hline Question & No. (\%) \\
\hline \multicolumn{2}{|c|}{$\begin{array}{l}\text { In the past } 12 \text { months, how often have you had a } \\
\text { drink containing alcohol? }\end{array}$} \\
\hline Never $($ score $=0$ ) & $702(41.3)$ \\
\hline Monthly or less (1) & $482(28.4)$ \\
\hline 2 to 4 times a month (2) & $267(15.7)$ \\
\hline 2 to 3 times a week (3) & $139(8.2)$ \\
\hline 4 or more times a week (4) & $109(6.4)$ \\
\hline \multicolumn{2}{|c|}{$\begin{array}{l}\text { In the past } 12 \text { months, how many drinks containing } \\
\text { alcohol have you had on a typical day when you } \\
\text { are drinking?a }\end{array}$} \\
\hline I don't drink (score = 0) & $797(46.9)$ \\
\hline 1 or $2(0)$ & $650(38.3)$ \\
\hline 3 or $4(1)$ & $162(9.5)$ \\
\hline 5 or $6(2)$ & $56(3.3)$ \\
\hline 7 to $9(3)$ & $18(1.1)$ \\
\hline 10 or more (4) & $16(0.9)$ \\
\hline \multicolumn{2}{|c|}{$\begin{array}{l}\text { In the past } 12 \text { months, how often have you had } \\
\text { six or more drinks on } 1 \text { occasion? }\end{array}$} \\
\hline Never (score $=0$ ) & $1,358(79.9)$ \\
\hline Less than monthly (1) & $211(12.4)$ \\
\hline Monthly (2) & $68(4.0)$ \\
\hline Weekly (3) & $47(2.8)$ \\
\hline Daily or almost daily (4) & $15(0.9)$ \\
\hline \multicolumn{2}{|c|}{$\begin{array}{l}\text { In the past } 12 \text { months, how often have you had a } \\
\text { lot more to drink that you intended to have? }\end{array}$} \\
\hline Never & $1,386(81.6)$ \\
\hline Less than monthly & $237(13.9)$ \\
\hline Monthly & $46(2.7)$ \\
\hline Weekly & $21(1.2)$ \\
\hline Daily or almost daily & $9(0.5)$ \\
\hline \multicolumn{2}{|c|}{$\begin{array}{l}\text { In the past } 12 \text { months, how often have you been } \\
\text { under the influence of alcohol in situations where } \\
\text { you could have caused an accident or gotten hurt? }\end{array}$} \\
\hline Never & $1,589(93.5)$ \\
\hline Less than monthly & $83(4.9)$ \\
\hline Monthly & $17(1.0)$ \\
\hline Weekly & $6(0.4)$ \\
\hline Daily or almost daily & $4(0.2)$ \\
\hline \multicolumn{2}{|c|}{$\begin{array}{l}\text { Classification of AUDIT-C scores based on sum } \\
\text { of } 3 \text { AUDIT-C items }{ }^{c}\end{array}$} \\
\hline Nondrinker & $683(40.2)$ \\
\hline Moderate Drinker & 654 (38.5) \\
\hline Hazardous & $362(21.3)$ \\
\hline \multicolumn{2}{|c|}{ Outcome based on 2-item DSM-IV screen ${ }^{d}$} \\
\hline Negative & $1,567(92.2)$ \\
\hline Positive & $132(7.8)$ \\
\hline \multicolumn{2}{|c|}{$\begin{array}{l}\text { Drinking status based on AUDIT-C Screen } \\
\text { and DSM-IV screen }\end{array}$} \\
\hline Nondrinker & $683(40.2)$ \\
\hline Moderate drinker & $637(37.5)$ \\
\hline Hazardous drinker & $379(22.3)$ \\
\hline
\end{tabular}

AUDIT-C = Alcohol Use Disorders Identification Test - Consumption; DSM-IV = Diagnostic and Statistical Manual of Mental Diseases, $4^{\text {th }}$ edition.

a AUDIT-C screening items.

${ }^{\mathrm{b}}$ DSM-IV screening items.

' Nondrinkers $=0$ drinks across 3 AUDIT-C items; female moderate drinkers $=1-2$ drinks and male moderate drinkers = 1-3 drinks; and female hazardous drinkers $=3-12$ drinks and male hazardous drinkers $=4-12$ drinks.

" Patients with a positive screen answered "monthly" or more often on either item or "less than monthly" on both items. 


\section{Table 3. Patient Self-Reported Alcohol Consumption: Composite of AUDIT-C and DSM-IV Screening Outcomes $(\mathrm{N}=1,699)$}

\begin{tabular}{|c|c|c|}
\hline AUDIT-C Outcome & DSM-IV Outcome & No. $(\%)^{a}$ \\
\hline \multicolumn{3}{|c|}{ AUDIT-C and DSM-IV screening outcomes } \\
\hline Nondrinker & Negative & $683(100,0)$ \\
\hline Moderate drinker & Negative & $637(97.4)$ \\
\hline Moderate drinker & Positive & $17(2.6)$ \\
\hline Hazardous drinker & Negative & $247(68.2)$ \\
\hline Hazardous drinker & Positive & $115(31.8)$ \\
\hline \multicolumn{3}{|c|}{$\begin{array}{l}\text { Composite of AUDIT-C and 1st DSM-IV } \\
\text { screening Item }\end{array}$} \\
\hline Nondrinker & Never & $683(100.0)$ \\
\hline Moderate drinker & Never & $561(85.8)$ \\
\hline Moderate drinker & $<$ Monthly & 89 (13.6) \\
\hline Moderate drinker & $\geq$ Monthly & $4(0.6)$ \\
\hline Hazardous drinker & Never & $142(39.2)$ \\
\hline Hazardous drinker & $<$ Monthly & $148(40.9)$ \\
\hline Hazardous drinker & zMonthly & $72(19.9)$ \\
\hline \multicolumn{3}{|c|}{$\begin{array}{l}\text { Composite of AUDIT-C and 2nd DSM-IV } \\
\text { screening Item }\end{array}$} \\
\hline Nondrinker & Never & $683(100.0)$ \\
\hline Moderate drinker & Never & $638(97.6)$ \\
\hline Moderate drinker & $<$ Monthly & $15(2.3)$ \\
\hline Moderate drinker & zMonthly & $1(0.2)$ \\
\hline Hazardous drinker & Never & $268(74.0)$ \\
\hline Hazardous drinker & $<$ Monthly & $68(18.8)$ \\
\hline Hazardous drinker & $\geq$ Monthly & $26(7.2)$ \\
\hline \multicolumn{3}{|c|}{$\begin{array}{l}\text { AUDIT-C = Alcohol Use Disorders Identification Test-Consumption; DSM-IV= Diagnostic and Statisti } \\
\text { Manual of Mental Diseases, 4th edition. }\end{array}$} \\
\hline \multicolumn{3}{|c|}{ a Percentages are calculated separately for each AUDIT-C outcome category. } \\
\hline
\end{tabular}

Compared with women, men were more likely to be moderate or hazardous drinkers. Hazardous drinkers were younger than moderate drinkers, who in turn were younger than nondrinkers. The probability of both moderate drinking and hazardous drinking increased as education increased from less than high school to college graduate.

In an ordered logistic regression model with drinking status as the dependent variable and controlling for clustering by clinician, men were more likely than women to report hazardous drinking, age was inversely related to alcohol involvement, and increasing educational attainment was associated with hazardous drinking. There were no associations between racial or ethnic identification and drinking status in bivariate or multivariate analyses.

\section{Sleep-Related Problems}

Most patients (61\%) reported sleeping on average less than 7 hours a night (Table 5). Initial insomnia ("not being able to get to sleep in 30 minutes") and late insomnia ("waking in the middle of

Table 4. Patient Demographics and Associations with Drinking Status $(\mathrm{N}=1,699)$

\begin{tabular}{|c|c|c|c|c|}
\hline Predictor Variable & $\begin{array}{l}\text { Nondrinkers } \\
\text { No. (\%) }\end{array}$ & $\begin{array}{c}\text { Moderate Drinkers } \\
\text { No. }(\%)\end{array}$ & $\begin{array}{c}\text { Hazardous Drinkers } \\
\text { No. (\%) }\end{array}$ & $\begin{array}{l}\text { Odds Ratio } \\
(95 \% \mathrm{Cl})\end{array}$ \\
\hline \multicolumn{5}{|l|}{ Sex } \\
\hline Female & $500(44.0)$ & $414(36.4)$ & $223(19.6)$ & $1.79^{\mathrm{b}}(1.42-2.25)$ \\
\hline Male & $183(32.6)$ & $223(39.7)$ & $156(27.8)$ & - \\
\hline Age, mean (SD), y & $54.5(18.0)$ & $49.0(16.2)$ & $45.7(16.8)$ & $0.98 / y(0.97-0.98)$ \\
\hline \multicolumn{5}{|l|}{ Education } \\
\hline Less than high school & $102(57.6)$ & $46(26.0)$ & $29(16.4)$ & $1.43^{c}(1.29-1.60)$ \\
\hline High school or GED & $268(49.7)$ & $183(34.0)$ & $88(16.3)$ & - \\
\hline Some college & $156(35.3)$ & $178(40.3)$ & $108(24.4)$ & - \\
\hline College or more & $157(29.0)$ & $230(42.5)$ & $154(28.5)$ & - \\
\hline \multicolumn{5}{|l|}{ Race and ethnicity } \\
\hline White & $485(39.5)$ & $469(38.2)$ & $274(22.3)$ & NS \\
\hline African American & $103(47.2)$ & $77(35.3)$ & $38(17.4)$ & - \\
\hline Hispanic & $52(37.4)$ & $55(39.6)$ & $32(23.0)$ & - \\
\hline Other & $37(37.0)$ & $31(31.0)$ & $32(32.0)$ & - \\
\hline Missing & $6(42.9)$ & $5(35.7)$ & $3(21.4)$ & - \\
\hline
\end{tabular}

GED = general equivalency diploma.

Note: percentages are row percentages, and may not add to $100 \%$ because of rounding.

a Odds ratios are from ordinal logistic regression with the 3-level drinking status as the dependent variable, controlling for clustering by clinician, sex, age, and educational attainment.

b Men vs women.

'Per level with this ordinal representation of educational attainment. 
Table 5. Responses of Patients to Survey Sleep Items and Associations with Drinking Status

\begin{tabular}{|c|c|c|c|c|c|}
\hline Sleep Variable (Column Percents Reported) & $\begin{array}{c}\text { Total } \\
\text { Sample } \\
\text { No. }(\%)\end{array}$ & $\begin{array}{l}\text { Nondrinkers } \\
\text { No. (\%) }\end{array}$ & $\begin{array}{l}\text { Moderate } \\
\text { Drinkers } \\
\text { No. (\%) }\end{array}$ & $\begin{array}{c}\text { Hazardous } \\
\text { Drinkers } \\
\text { No. (\%) }\end{array}$ & OR $(95 \% \mathrm{Cl})^{\mathrm{a}}$ \\
\hline \multicolumn{6}{|c|}{$\begin{array}{l}\text { During past } 30 \text { days, how many hours of sleep have you typically } \\
\text { had each night? }\end{array}$} \\
\hline$<5$ & $226(13)$ & $105(15)$ & $69(11)$ & $52(14)$ & NS \\
\hline 5 to 6 & $804(47)$ & $307(45)$ & $313(49)$ & $184(49)$ & - \\
\hline 7 to 9 & $627(37)$ & $249(37)$ & $241(38)$ & $137(36)$ & - \\
\hline$\geq 10$ & $42(3)$ & $22(3)$ & $14(2)$ & $6(2)$ & - \\
\hline \multicolumn{6}{|c|}{$\begin{array}{l}\text { During past } 30 \text { days, how often have you had trouble sleeping } \\
\text { because you could not get to sleep within } 30 \text { minutes? }\end{array}$} \\
\hline 0 & $502(30)$ & $196(29)$ & $194(31)$ & $112(30)$ & NS \\
\hline$<1$ time/wk & $371(22)$ & $132(19)$ & $148(23)$ & $91(24)$ & - \\
\hline 1-2 times/wk & $360(21)$ & $151(22)$ & $134(21)$ & $75(20)$ & - \\
\hline$\geq 3$ times/wk & $461(27)$ & $200(30)$ & $160(25)$ & $101(27)$ & - \\
\hline \multicolumn{6}{|c|}{$\begin{array}{l}\text { During past } 30 \text { days, how often have you had trouble sleeping } \\
\text { because you woke up in middle of night or early morning? }\end{array}$} \\
\hline 0 & $391(23)$ & $159(23)$ & $146(23)$ & $86(23)$ & NS \\
\hline$<1$ time/wk & $365(22)$ & 124 (18) & $143(23)$ & $98(26)$ & - \\
\hline $1-2$ times/wk & $365(22)$ & $137(20)$ & $151(24)$ & $77(20)$ & - \\
\hline$\geq 3$ times/wk & $571(34)$ & $260(38)$ & $194(31)$ & 117 (31) & - \\
\hline \multicolumn{6}{|c|}{ During past 30 days, how would you rate your sleep quality overall? } \\
\hline Excellent & $108(6)$ & $47(7)$ & $38(6)$ & $23(6)$ & NS \\
\hline Very good & $288(17)$ & $114(17)$ & $112(18)$ & $62(16)$ & - \\
\hline Good & 487 (29) & $185(27)$ & $189(30)$ & $113(30)$ & - \\
\hline Fair & $519(31)$ & $190(28)$ & $203(32)$ & $126(33)$ & - \\
\hline Poor & $289(17)$ & $145(21)$ & $90(14)$ & $54(14)$ & - \\
\hline \multicolumn{6}{|c|}{$\begin{array}{l}\text { During past } 30 \text { days, how often have you had trouble sleeping because you } \\
\text { had a restless feeling in your legs that went away if you moved our legs? }\end{array}$} \\
\hline 0 & 1,095 (66) & $416(62)$ & 419 (67) & $260(69)$ & NS \\
\hline$<1$ time/wk & $209(13)$ & $85(13)$ & $83(13)$ & $41(11)$ & - \\
\hline 1-2 times/wk & $180(11)$ & $75(11)$ & $64(10)$ & $41(11)$ & - \\
\hline$\geq 3$ times/wk & $189(11)$ & $92(14)$ & $62(10)$ & $35(9)$ & - \\
\hline \multicolumn{6}{|c|}{$\begin{array}{l}\text { During past } 30 \text { days, how often have you had trouble staying awake } \\
\text { while driving, eating meals, or engaging in social activities? }\end{array}$} \\
\hline 0 & $1,259(76)$ & $514(79)$ & $470(75)$ & $275(73)$ & NS \\
\hline$<1$ time/wk & $195(12)$ & $62(10)$ & $88(14)$ & $45(12)$ & - \\
\hline $1-2$ times/wk & $130(8)$ & $50(8)$ & $46(7)$ & $34(9)$ & - \\
\hline$\geq 3$ times/wk & $70(4)$ & $27(4)$ & $22(4)$ & $21(6)$ & - \\
\hline \multicolumn{6}{|l|}{ Sleep apnea } \\
\hline No diagnosis, & $1,563(93)$ & $614(90)$ & $593(94)$ & $356(94)$ & $0.61(0.38-0.999)^{b}$ \\
\hline Diagnosis by a clinician or treatment for it & $124(7)$ & $65(10)$ & $37(6)$ & $22(6)$ & $0.60(0.34-1.08)^{c}$ \\
\hline \multicolumn{6}{|c|}{$\begin{array}{l}\text { During past } 30 \text { days, how often have you taken medicine (prescribed } \\
\text { or "over-the-counter") in order to sleep? }\end{array}$} \\
\hline 0 & $1,129(68)$ & $445(67)$ & $441(70)$ & $243(65)$ & NS \\
\hline$<1$ time/wk & $106(6)$ & $33(5)$ & $51(8)$ & $22(6)$ & - \\
\hline $1-2$ times/wk & $110(7)$ & $43(7)$ & $41(7)$ & $26(7)$ & - \\
\hline$\geq 3$ times/wk & $322(19)$ & $140(21)$ & $97(15)$ & $85(23)$ & - \\
\hline \multicolumn{6}{|c|}{ During past 30 days, how often have your used alcohol in order to sleep? } \\
\hline 0 & $1,492(92)$ & $617(98)$ & $587(94)$ & $288(78)$ & $4.53(2.94-6.97)^{\mathrm{e}}$ \\
\hline$<1$ time/wk & $62(4)$ & $10(2)^{d}$ & $21(3)$ & $31(8)$ & - \\
\hline $1-2$ times/wk & $45(3)$ & $1(0)^{\mathrm{d}}$ & $11(2)$ & $33(9)$ & - \\
\hline$\geq 3$ times/wk & $26(2)$ & $3(1)^{\mathrm{d}}$ & $4(1)$ & $19(5)$ & - \\
\hline
\end{tabular}

$\mathrm{Cl}=$ confidence interval; $\mathrm{OR}=$ odds ratio.

Note: percentages may not add to $100 \%$ because of rounding.

a Examining each listed sleep item as the dependent variable in either a logistic regression model (for dichotomous sleep variables, with odds ratios) or linear regression model (for continuous ones), controlling for sex, age, educational attainment, and clustering by clinician.

${ }^{b}$ Comparing moderate with nondrinkers.

'Comparing hazardous with nondrinkers.

"These 14 patients answered all 5 alcohol questions "Never" or "I don't drink." Their responses on this question are clearly inconsistent.

e Comparing hazardous with moderate drinkers, omitting nondrinkers. and entering frequency of using alcohol for sleep as once a month or more often. 
the night") were both common, and $39 \%$ of the patients reported both conditions at least once a week. Fortyeight percent reported that their overall sleep quality was fair or poor, $21 \%$ had symptoms of restless leg syndrome ("had trouble sleeping because of restless feeling in legs"), and $12 \%$ reported daytime somnolence ("had trouble staying awake" during daytime activities).

One-fourth of the patients reported "taking medications (prescribed or over-the-counter) for sleep" at least once per week, and $4 \%$ indicated "drinking alcohol in order to sleep" at least once per week (8\% reported "within last month"). A diagnosis of or treatment for sleep apnea was reported by $7 \%$ of patients.

\section{Drinking Status and Sleep Problems}

In bivariate $\chi^{2}$ and Kruskal-Wallis analyses, no significant associations were observed between drinking status and hours slept per night, early insomnia, late insomnia, using medications for sleep, daytime somnolence, or overall sleep quality. Symptoms of restless leg syndrome $(P=.03)$, sleep apnea $(P=.02)$, and using alcohol for sleep $(P<.001)$ were significantly associated with drinking status. For this last analysis, 14 (2\%) of 683 nondrinkers reported that they had used alcohol to sleep at least once during past month, although they had answered negatively to each of 5 drinking items. Excluding these 14 cases from this specific analysis did not change the results.

In multivariate analyses with each of these sleep problems controlling for patient demographics and clustering by clinician, use of alcohol for sleep remained significantly associated with drinking status both when it was entered as a continuous variable in linear regression and as a dichotomous one in logistic regression (any reported use vs none in the last month). The adjusted analyses (last column Table 5) showed that moderate and hazardous drinking were associated with lower likelihood of sleep apnea compared with nondrinkers. Only 1 of the associations (moderate drinkers vs nondrinkers) was statistically significant, however, and that only marginally. Sleep apnea was more likely to be reported by men and also associated with older age (not shown). None of the other sleep problems were associated with drinking status in multivariate analyses.

Use of alcohol for sleep (any reported use vs none in the last month) was strongly associated with hazardous drinking in logistic regression. Omitting nondrinkers $(n=683)$, the odds ratio for hazardous drinkers was 4.53. Men were more likely to report past-month use of alcohol for sleep than women (not shown). Excluding nondrinkers, the sensitivity of this item in detecting hazardous drinking was $22.4 \%$ and the specificity $94.2 \%$.

\section{DISCUSSION}

Hazardous drinking and several sleep problems were prevalent in this large cross-sectional national survey of patients seen in primary care. Almost 20\% of women and more than one-fourth of men met screening criteria for hazardous drinking, higher prevalence rates than in reported in previous population-based ${ }^{8,9}$ and primary care studies. ${ }^{33,34}$ Almost one-half of all respondents reported only "fair" or "poor" overall sleep quality in the past 30 days. One-fourth reported using an over-the-counter or prescription medication for sleep at least once a week. Multivariate analyses showed no associations between drinking status and self-reported measures of insomnia, overall sleep quality, or restless legs syndrome symptoms.

A self-reported diagnosis of or treatment for sleep apnea was reported more commonly by patients who did not drink than by moderate or hazardous drinkers. Moderate drinking and hazardous drinking were associated with a $40 \%$ reduction in the odds of reporting sleep apnea, which was marginally statistically significant for moderate drinkers vs nondrinkers. In a cross-sectional study that included a population-based sample of 1,420 people in Wisconsin, each incremental drink per day was associated in men (but not women) with a $25 \%$ increase in the risk of having polysomnographically documented sleep apnea. ${ }^{35}$ The Wisconsin sample did not include heavy drinkers or persons who reported recent major changes in their drinking habits. Furthermore, persons were excluded if they had major problems sleeping in a laboratory. The discordance between our findings and those in the Wisconsin study may be due to differences in how sleep apnea was identified (simple self-report vs formal sleep study) or, in our sample, by changes in patients' alcohol consumption because of counseling in treating newly diagnosed sleep apnea.

Previous studies of the relationship between alcohol and sleep problems have varied in their findings. The studies cited by Stein and Friedmann in their review ${ }^{20}$ used a variety of measures of alcohol use and sleep problems. A study of Epidemiologic Catchment Area data reported that DSM-III-defined alcohol use disorders were associated with a more than twofold greater adjusted odds of insomnia, defined as insomnia for 2 or more weeks in the past 6 months. ${ }^{36}$ Among patients with a chronic disease in the Medical Outcomes Study, there was no significant association between insomnia and alcohol use, with alcohol measured simply as never, past, or current use. ${ }^{37}$ Most laboratory studies have consistently found that moderate alcohol consumption acutely and negatively affects sleep. ${ }^{38,39}$

We found that self-reported use of alcohol for sleep was strongly associated with hazardous drinking, with 
an odds ratio of 4.5. Previous studies have examined alcohol use for a sleep aid and found it commonly reported, but did not examine hazardous drinking or alcohol problems. ${ }^{40,41}$ Use of alcohol to sleep might be used as a cue to inquire further about hazardous drinking or alcohol problems. The positive predictive value of using this question to detect hazardous drinking was $62.4 \%$ among all patients and $69.8 \%$ among all drinkers, and the negative predictive value (excluding nondrinkers) is likewise moderate at $67.1 \%$.

In our study, sex, age, and educational attainment (but not race) were associated with hazardous drinking. Some studies have reported a similar positive relationship of alcohol problems and increasing education level, ${ }^{9}$ whereas others have reported a negative relationship. ${ }^{42,43}$

The lack of other associations between sleep problems and drinking status in our study is unlikely to be due to underreporting of alcohol consumption or alcohol-related problems. Prevalence of hazardous drinking was higher than in other studies. ${ }^{8,9}$

\section{Limitations}

Identification of episodic heavy drinking, alcohol use disorders, and sleep problems was based solely on patient self-reports, which may be limited by problems with understanding, recall, or candor. More thorough and validated patient instruments for identifying sleep apnea and restless leg syndrome in primary care are available ${ }^{44-46}$ and could be considered for future studies. For patients reporting medications to aid in sleep, we did not inquire as to which medications were used. Furthermore, we did not ask about smoking or weight, which are potential confounders in the associations examined here.

We also did not stratify hazardous drinkers into subcategories based on either AUDIT-C or DSM-IV screening to investigate whether sleep problems varied across the severity of alcohol consumption. Of the 379 hazardous drinkers, only 5\% had an AUDIT-C score greater than 6. Given the relatively few patients in this study whose self-reports would classify them as "severe" hazardous drinkers (upper end of scale), we were constrained in our attempts to consider how this subgroup compares with other drinkers in their prevalence of sleep problems.

In this cross-sectional study of a large number of adult patients seen in a wide variety of primary care practices, moderate and hazardous drinking were not associated with the self-reported sleep problems as originally hypothesized. Using alcohol for sleep, however, was strongly associated with hazardous drinking relative to moderate drinking and may serve as a prompt for physicians to ask about excessive alcohol use.

To read or post commentaries in response to this article, see it online at http://www.annfammed.org/cgi/content/full/8/6/484.
Key words: Alcohol-related disorders; sleep disorders, intrinsic; sleep apnea; practice-based research

Submitted December 2, 2009; submitted, revised, April 11, 2010; accepted May 14, 2010.

Funding support: This study was funded by a grant from the Robert Wood Johnson Foundation to the University of Pennsylvania, "Program of Research Integrating Substance Use Information into Mainstream Healthcare," Barbara J. Turner, MD, MSED, MA, principal investigator.

Finding from this study have been previously reported a the Annual Conference of the North American Primary Care Research Group (NAP(RG) in San Juan, Puerto Rico on November 16, 2008.

Acknowledgments: The authors acknowledge the collaboration of the AAFP National Research Network's affiliate networks, medical practices, study physicians, and practice study coordinators who executed the research protocol at their locations. We thank the following for their contributions: the Kentucky Ambulatory Network (KAN); Research Involving Outpatient Settings Network (RIOSNet); Missouri's Show-Me Research Network; State Networks of Colorado Ambulatory Practices and Partners (SNOCAP); Alber Abrahim, MD; Rich Allen, MD, MPH; Roger Austin, PA; Ravi Balasubrahmanyan, MD; William H. Bayer, MD; Terrell Benold, MD; Robby Bershow, MD; Jennifer Brull, MD; Edward Bujold, MD; Linnea Cairney, RN; Samuel Church, MD, MPH; Sarah Curry, MD; Joel Dickerman, DO; Tillman Farley, MD; John Farmer, DO; Scott E. Faulkner, MD; Mitchell Finnie, MD; Lynn Fisher, MD; Michael Fortunato, MD; Chester Fox, MD; Aregai Girmay, MD; Katie Guthrie, MD; David L. Hahn, MD; Douglas Hammer, MD, DrPH; Lisa Holland, MD; Sue Inoue, MD; David S. Johnson, MD; Namita Joshi, MD; Raj Kachoria, MD; Kim Krohn, MD, MPH; William D. Lee, MD; Stacy Longnecker, MD; Barbara Lopez, MD; Chris Lupold, MD; Kathleen Macken, MD; Jeanne Mase, MD; Susan McMaster, MD; Yenni Michel, DO; Nickolas Modjeski, MD; Jinny Narula, MD; Chinyere Njoku, MD; Shirley Ocloo, MD; Venna Panthangi, MD; Michael L. Parchman, MD; John Patton, MD; Tammy Pearson, RN, LMSW; Darlene Peterson, MD; Bridget Pribbenow, MD; Marina Raikhel, MD; Derek Rasmussen, MD; Wayne Reynolds, MD; Eugene Reynolds, MD; David Ross, MD; Guy Runkle, MD; Himanshu Sharma, MD; Elisabeth Spector, MD, MPH; Linda Stewart, MD; Lucy Walker, MD; Patricia West, PhD, RN; Glenn Womack, MD; and Frances Wu, MD.

\section{References}

1. Mertens JR, Weisner C, Ray GT, Fireman B, Walsh K. Hazardous drinkers and drug users in $\mathrm{HMO}$ primary care: prevalence, medical conditions, and costs. Alcohol Clin Exp Res. 2005;29(6):989-998.

2. Rehm J, Gmel G, Sempos CT, Trevisan M. Alcohol-related morbidity and mortality. Alcohol Res Health. 2003:27(1):39-51.

3. Saitz R. Clinical practice. Unhealthy alcohol use. $N$ Engl J Med. 2005;352(6):596-607.

4. Mokdad AH, Marks JS, Stroup DF, Gerberding JL. Actual causes of death in the United States, 2000. JAMA. 2004;291(10):1238-1245.

5. Chen CM, Hsaio-ye Y. Trends in Alcohol-Related Morbidity among Short-Stay Community Hospital Discharges, United States, 19792006. Surveillance Report \# 84. Alcohol Epidemiologic Data System, National Institute on Alcohol Abuse and Alcoholism. 2008. http://pubs .niaaa.nih.gov/publications/surveillance84/HDS06.pdf. Updated 2008.

6. McCaig LF, Burt CW. National Hospital Ambulatory Medical Care Survey: 2003 Emergency Department Summary. Advance Data from Vital and Health Statistics; Number 358. Centers for Disease Control and Prevention. 2005. http://www.cdc.gov/nchs/data/ad lad358.pdf. Updated 2005. 
7. Harwood $\mathrm{H}$. Updating estimates of the economic costs of alcohol abuse in the United States: estimates, update methods, and data. http://pubs.niaaa.nih.gov/publications/economic-2000/. Updated 2000.

8. Centers for Disease Control and Prevention. Behavioral Risk Factor Surveillance System Survey Data. Atlanta, FA: Centers for Disease Control and Prevention. 2008. http://apps.nccd.cdc.gov/BRFSS/. Updated August 6, 2009. Accessed Nov 30, 2009.

9. Hasin DS, Stinson FS, Ogburn E, Grant BFP. Prevalence, correlates, disability, and comorbidity of DSM-IV alcohol abuse and dependence in the United States: results from the National Epidemiologic Survey on Alcohol and Related Conditions. Arch Gen Psychiatry. 2007;64(7):830-842.

10. McGlynn EA, Asch SM, Adams J, et al. The quality of health care delivered to adults in the United States. N Engl J Med. 2003;348 (26):2635-2645

11. Solberg LI, Maciosek MV, Edwards NM. Primary care intervention to reduce alcohol misuse ranking its health impact and cost effectiveness. Am J Prev Med. 2008;34(2):143-152.

12. Miller PM, Thomas SE, Mallin R. Patient attitudes towards selfreport and biomarker alcohol screening by primary care physicians. Alcohol Alcohol. 2006;41(3):306-310.

13. Whitlock EP, Polen MR, Green CA, Orleans T, Klein J: U.S. Preventive Services Task Force. Behavioral counseling interventions in primary care to reduce risky/harmful alcohol use by adults: a summary of the evidence for the U.S. Preventive Services Task Force. Ann Intern Med. 2004;140(7):557-568.

14. Beich A, Gannik D, Malterud K. Screening and brief intervention for excessive alcohol use: qualitative interview study of the experiences of general practitioners. BMJ. 2002;325(7369):870.

15. Rush BR, Powell LY, Crowe TG, Ellis K. Early intervention for alcohol use: family physicians' motivations and perceived barriers. CMAJ. 1995;152(6):863-869.

16. Turner BJ, McLellan AT. Methodological challenges and limitations of research on alcohol consumption and effect on common clinica conditions: evidence from six systematic reviews. J Gen Intern Med. 2009;24(10):1156-1160.

17. Ancoli-Israel S, Roth T. Characteristics of insomnia in the United States: results of the 1991 National Sleep Foundation Survey. I. Sleep. 1999;22(Suppl 2):S347-S353.

18. Simon GE, VonKorff M. Prevalence, burden, and treatment of insomnia in primary care. Am J Psychiatry. 1997;154(10):1417-1423.

19. Alattar M, Harrington JJ, Mitchell CM, Sloane P. Sleep problems in primary care: a North Carolina Family Practice Research Network (NC-FP-RN) study. J Am Board Fam Med. 2007;20(4):365-374

20. Stein MD, Friedmann PD. Disturbed sleep and its relationship to alcohol use. Subst Abus. 2005;26(1):1-13.

21. Jefferson $C D$, Drake $C L$, Scofield HM, et al. Sleep hygiene practices in a population-based sample of insomniacs. Sleep. 2005;28(5):611-615.

22. Rupp TL, Acebo C, Van Reen E, Carskadon MA. Effects of a moderate evening alcohol dose. I: sleepiness. Alcohol Clin Exp Res. 2007; 31(8):1358-1364.

23. Roehrs T, Roth T. Sleep, sleepiness, and alcohol use. Alcohol Res Health. 2001;25(2):101-109.

24. Weissman MM, Greenwald S, Niño-Murcia G, Dement WC. The morbidity of insomnia uncomplicated by psychiatric disorders. Gen Hosp Psychiatry. 1997;19(4):245-250.

25. NRN looking for participants in alcohol and sleep problems study. AAFP News Now. September 2007.

26. Buysse DJ, Reynolds CF III, Monk TH, Berman SR, Kupfer DJ. The Pittsburgh Sleep Quality Index: a new instrument for psychiatric practice and research. Psychiatry Res. 1989;28(2):193-213.
27. Roth $T$, Zammit $G$, Kushida $C$, et al. A new questionnaire to detect sleep disorders. Sleep Med. 2002;3(2):99-108.

28. Saunders JB, Aasland OG, Babor TF, de la Fuente JR, Grant M. Development of the Alcohol Use Disorders Identification Test (AUDIT): WHO Collaborative Project on Early Detection of Persons with Harmful Alcohol Consumption-II. Addiction. 1993;88(6):791-804.

29. Bradley KA, DeBenedetti AF, Volk RJ, Williams EC, Frank D, Kivlahan DR. AUDIT-C as a brief screen for alcohol misuse in primary care. Alcohol Clin Exp Res. 2007;31(7):1208-1217.

30. Vinson DC, Kruse RL, Seale JP. Simplifying alcohol assessment: two questions to identify alcohol use disorders. Alcohol Clin Exp Res. 2007;31(8):1392-1398.

31. Kelly TM, Donovan JE, Chung T, Bukstein OG, Cornelius JR. Brief screens for detecting alcohol use disorder among 18-20 year old young adults in emergency departments: Comparing AUDIT-C, CRAFFT, RAPS4-QF, FAST, RUFT-Cut, and DSM-IV 2-Item Scale. Addict Behav. 2009;34(8):668-674.

32. Diagnostic and Statistical Manual of Mental Disorders, 4th Edition (DSM-IV). Arlington, VA: American Psychiatric Association; 1994

33. Anderson P. Management of alcohol problems: the role of the general practitioner. Alcohol Alcohol. 1993;28(3):263-272.

34. Fleming MF, Manwell LB, Barry KL, Johnson K. At-risk drinking in an $\mathrm{HMO}$ primary care sample: prevalence and health policy implications. Am J Public Health. 1998;88(1):90-93.

35. Peppard PE, Austin D, Brown RL. Association of alcohol consumption and sleep disordered breathing in men and women. J Clin Sleep Med. 2007;3(3):265-270.

36. Ford DE, Kamerow DB. Epidemiologic study of sleep disturbances and psychiatric disorders. An opportunity for prevention? JAMA. 1989;262(11):1479-1484.

37. Katz DA, McHorney CA. Clinical correlates of insomnia in patients with chronic illness. Arch Intern Med. 1998;158(10):1099-1107.

38. Tsutsumi W, Miyazaki S, Itasaka Y, Togawa K. Influence of alcohol on respiratory disturbance during sleep. Psychiatry Clin Neurosci. 2000;54(3):332-333.

39. Young T, Peppard PE, Gottlieb DJ. Epidemiology of obstructive sleep apnea: a population health perspective. Am J Respir Crit Care Med. 2002;165(9):1217-1239.

40. Daley M, Morin CM, LeBlanc M, Grégoire JP, Savard J, Baillargeon $\mathrm{L}$. Insomnia and its relationship to health-care utilization, work absenteeism, productivity and accidents. Sleep Med. 2009;10(4): 427-438.

41. Kaneita Y, Uchiyama M, Takemura S, et al. Use of alcohol and hypnotic medication as aids to sleep among the Japanese general population. Sleep Med. 2007;8(7-8):723-732.

42. Crum RM, Anthony JC. Educational level and risk for alcohol abuse and dependence: differences by race-ethnicity. Ethn Dis. 2000;10(1) $39-52$.

43. Gilman SE, Breslau J, Conron KJ, Koenen KC, Subramanian SV Zaslavsky AM. Education and race-ethnicity differences in the lifetime risk of alcohol dependence. J Epidemiol Community Health. 2008;62(3):224-230.

44. Nichols DA, Allen RP, Grauke JH, et al. Restless legs syndrome symptoms in primary care: a prevalence study. Arch Intern Med. 2003: 163(19):2323-2329.

45. Ramachandran SK, Josephs LA. A meta-analysis of clinical screening tests for obstructive sleep apnea. Anesthesiology. 2009; 110(4):928-939.

46. Chung $F$, Yegneswaran B, Liao $P$, et al. Validation of the Berlin questionnaire and American Society of Anesthesiologists checklist as screening tools for obstructive sleep apnea in surgical patients. Anesthesiology. 2008;108(5):822-830. 